\title{
Proteasome inhibition reverses hedgehog inhibitor and taxane resistance in ovarian cancer
}

\author{
Adam D. Steg ${ }^{1,2, *}$, Mata R. Burke ${ }^{1, *}$, Hope M. Amm ${ }^{3}$, Ashwini A. Katre ${ }^{1}$, Zachary C. \\ Dobbin ${ }^{1}$, Dae Hoon Jeong ${ }^{4}$ and Charles N. Landen ${ }^{5, *}$ \\ ${ }^{1}$ Department of Obstetrics and Gynecology, University of Alabama at Birmingham, Birmingham, AL \\ ${ }^{2}$ McWhorter School of Pharmacy, Samford University, Birmingham, AL \\ ${ }^{3}$ Institute of Oral Health Research, University of Alabama at Birmingham, Birmingham, AL \\ 4 Department of Obstetrics and Gynecology Busan Paik Hospital, Inje University, Gimhae, South Korea \\ ${ }^{5}$ Department of Obstetrics and Gynecology, University of Virginia, Charlottesville, VA \\ * These authors contributed equally to this work
}

Correspondence to: Charles N. Landen, email: clanden@virginia.edu

Keywords: bortezomib, LDE225, paclitaxel, hedgehog, proteasome, ovarian cancer

Received: June 03, $2014 \quad$ Accepted: July 31, 2014

Published: July31, 2014

This is an open-access article distributed under the terms of the Creative Commons Attribution License, which permits unrestricted use, distribution, and reproduction in any medium, provided the original author and source are credited.

\section{ABSTRACT}

The goal of this study was to determine whether combined targeted therapies, specifically those against the Notch, hedgehog and ubiquitin-proteasome pathways, could overcome ovarian cancer chemoresistance. Chemoresistant ovarian cancer cells were exposed to gamma-secretase inhibitors (GSI-I, Compound E) or the proteasome inhibitor bortezomib, alone and in combination with the hedgehog antagonist, LDE225. Bortezomib, alone and in combination with LDE225, was evaluated for effects on paclitaxel efficacy. Cell viability and cell cycle analysis were assessed by MTT assay and propidium iodide staining, respectively. Proteasome activity and gene expression were determined by luminescence assay and QPCR, respectively. Studies demonstrated that GSI-I, but not Compound E, inhibited proteasome activity, similar to bortezomib. Proteasome inhibition decreased hedgehog target genes (PTCH1, GLI1 and GLI2) and increased LDE225 sensitivity in vitro. Bortezomib, alone and in combination with LDE225, increased paclitaxel sensitivity through apoptosis and $\mathrm{G2} / \mathrm{M}$ arrest. Expression of the multi-drug resistance gene ABCB1/MDR1 was decreased and acetylation of a-tubulin, a marker of microtubule stabilization, was increased following bortezomib treatment. HDAC6 inhibitor tubastatin-a demonstrated that microtubule effects are associated with hedgehog inhibition and sensitization to paclitaxel and LDE225. These results suggest that proteasome inhibition, through alteration of microtubule dynamics and hedgehog signaling, can reverse taxanemediated chemoresistance.

\section{INTRODUCTION}

Ovarian cancer is the leading cause of death from a gynecologic malignancy. Although ovarian cancer is among the most chemosensitive malignancies at the time of initial treatment (consisting of surgery and platinum/ taxane-based chemotherapy), most patients will develop tumor recurrence and succumb to chemoresistant disease [1]. Evaluation of multiple chemotherapy agents in several combinations in the last 20 years has yielded modest improvements in progression-free survival, but no increase in durable cures. This clinical course suggests that multiple cellular pathways contribute to either inherent or acquired resistance to chemotherapy. Targeting these cellular pathways with combination therapies may provide better long-term outcomes if the chemoresistant population can be identified and targeted.

Cellular pathways normally involved in embryonic development, including Notch and hedgehog, have been found to be aberrantly expressed in a variety of 
malignancies [2-4], including ovarian cancer [5-11], and may be especially important in conferring resistance to chemotherapies [12-16]. Thus, inhibition of these pathways may offer valuable therapeutic strategies against ovarian cancer, either alone or as chemosensitizing agents. In particular, compounds that target gamma-secretase, which is crucial for Notch signaling activation [17], have been evaluated as potential anti-cancer agents. In addition, compounds have been developed that antagonize the Smoothened receptor, a mediator of hedgehog signaling [18]. One of these compounds, LDE225, has been used to target cancer cells in both pre-clinical and clinical models [18-21].

The ubiquitin-proteasome pathway is responsible for maintaining cellular homeostasis by regulating the degradation of proteins. Disruption of this pathway can result in cell cycle arrest and apoptosis as a result of incompatible regulatory protein accumulation within the cell [22]. Cancer cells generally have higher levels of proteasome activity and are more sensitive to the proapoptotic effects of proteasome inhibition than normal cells, making the proteasome a desirable therapeutic target [23]. Bortezomib is a dipeptidyl boronic acidbased reversible proteasome inhibitor that targets the chymotrypsin- and caspase-like active sites of the proteasome complex [24]. This compound was the first proteasome inhibitor to be approved for clinical use and is commonly used in the treatment of hematologic malignancies, including multiple myeloma and mantle cell lymphoma [25]. By inhibiting the proteasome, bortezomib acts through several mechanisms to suppress tumor survival pathways and to arrest tumor growth, metastasis and angiogenesis. These mechanisms of action have provided rationale for the combination of bortezomib with numerous chemotherapeutic and targeted agents [2628 ], some of which have been evaluated in ovarian cancer clinical trials [29-31].

Novel therapeutic strategies targeting chemoresistant cells are essential to achieving durable cures in ovarian cancer. In our study, we sought to reverse resistance to chemotherapeutic and targeted agents using different pharmacological strategies. The results of this study demonstrate several novel mechanisms. First, the variable response seen with different gamma-secretase inhibitors is due to differential effects on the proteasome. Secondly, proteasome inhibition affects microtubule stabilization in a manner similar to taxanes and increases sensitivity to paclitaxel. Finally, proteasome inhibition alone reduces hedgehog pathway signaling and as a result is synergistic with hedgehog antagonist LDE225. The demonstrated crossover between these pathways sheds new light onto the contributing mechanisms of chemotherapy resistance in ovarian cancer and provides new opportunities for clinical development.

\section{RESULTS}

\section{In vitro resistance to the Smoothened antagonist, LDE225, can be reversed by the gamma-secretase inhibitor GSI-I but not compound $E$}

We first sought to examine the mechanisms of dual inhibition of the Notch and Hedgehog pathways in three chemoresistant ovarian cancer cell lines: A2780cp55 (platinum- and taxane-resistant), HeyA8MDR (taxaneresistant) and SKOV3TRip2 (taxane-resistant). Dosedependent growth inhibition with LDE225 alone is shown in Figure 1A. The decrease in A2780cp55 and HeyA8MDR cell viability following LDE225 treatment is similar $(39.7 \%$ versus $38.2 \%$ decrease at $5 \mu \mathrm{M}$ and $56.7 \%$ versus $60.1 \%$ decrease at $10 \mu \mathrm{M})$. However, SKOV3TRip2 cells responded to LDE225 to a lesser extent by comparison (13.5\% and $35.4 \%$ decrease at 5 and $10 \mu \mathrm{M}$, respectively), suggesting that these cells have an innate mechanism of resistance to LDE225. Therefore, further combination strategies were pursued in this line in an attempt to uncover mechanisms of resistance to hedgehog inhibition.

Having previously demonstrated crosstalk between the Notch and Hedgehog pathways in SKOV3TRip2 cells [32], we wanted to determine if targeting the Notch pathway using gamma-secretase inhibitors could have an effect on response to LDE225 in these cells. To this end, we examined the effect of 2 different gamma-secretase inhibitors, GSI-I and GSI-XXI (Compound E) on the viability of SKOV3TRip2 cells. Interestingly, the viability of these cells was decreased following exposure to GSI-I, but not to Compound E (Figure 1B). Used in combination, GSI-I increased the sensitivity of SKOV3TRip2 cells to LDE225; up to a 17-fold decrease in the LDE225 IC50 compared to DMSO control was observed, suggesting a synergistic interaction (Figure 1C). Calculation of a combination index $(\mathrm{CI}=0.44$ at $2 \mu \mathrm{M}, \mathrm{CI}=0.11$ at $3 \mu \mathrm{M})$ confirms a synergistic effect. This effect was not observed with LDE225 in combination with Compound E (Figure 1D), suggesting that these gamma-secretase inhibitors may have differential mechanisms of action.

To determine if Notch inhibition is playing a role in LDE225 sensitization, knockdown of Notch signaling components (Notch1, Notch2, Notch3 and Jagged1) was carried out using siRNA. These siRNAs have previously been shown by our laboratory to decrease the mRNA levels of their respective target genes by up to $85 \%$ [32]. Alone, knockdown of these individual genes decreased SKOV3TRip2 cell viability (by $65.1 \%, 29.3 \%, 45.7 \%$ and $73.3 \%$, respectively; $\mathrm{p}<0.05$ ) compared to siRNA control, indicating that Notch signaling does contribute to the survival of these cells (Figure 1E). However, none of these siRNAs had a significant sensitizing effect on 
LDE225, as demonstrated by parallel dose response curves (Figure 1E) compared to the siRNA control. The fact that independent Notch family targeting and Compound E could not sensitize to hedgehog inhibition, as GSI-I could, suggest that the mechanism by which GSI-I sensitizes SKOV3TRip2 cells to LDE225 is independent of Notch inhibition.

\section{Proteasome inhibition reverses LDE225 resistance in SKOV3TRip2 cells}

Previous studies have demonstrated that GSI-I can act as a proteasome inhibitor [33-35]. To determine if
GSI-I sensitizes SKOV3TRip2 cells to LDE225 through this mechanism rather than gamma-secretase inhibition, we first examined the effects of GSI-I, Compound E and bortezomib (a known proteasome inhibitor) on proteasome activity. In agreement with previous studies, both GSI-I and bortezomib produced a dose-dependent decrease in proteasome activity by up to $51.6 \%$ and $71.0 \%$, respectively $(\mathrm{p}<0.05)$, whereas Compound E did not (Figure 2A). Moreover, treatment with GSI-I or bortezomib resulted in a significant increase in polyubiquitinated proteins, an indicator of proteasome inhibition [33] (Figure 2B). When combined with LDE225, bortezomib produced a similar synergistic effect on the viability of SKOV3TRip2 cells as that observed
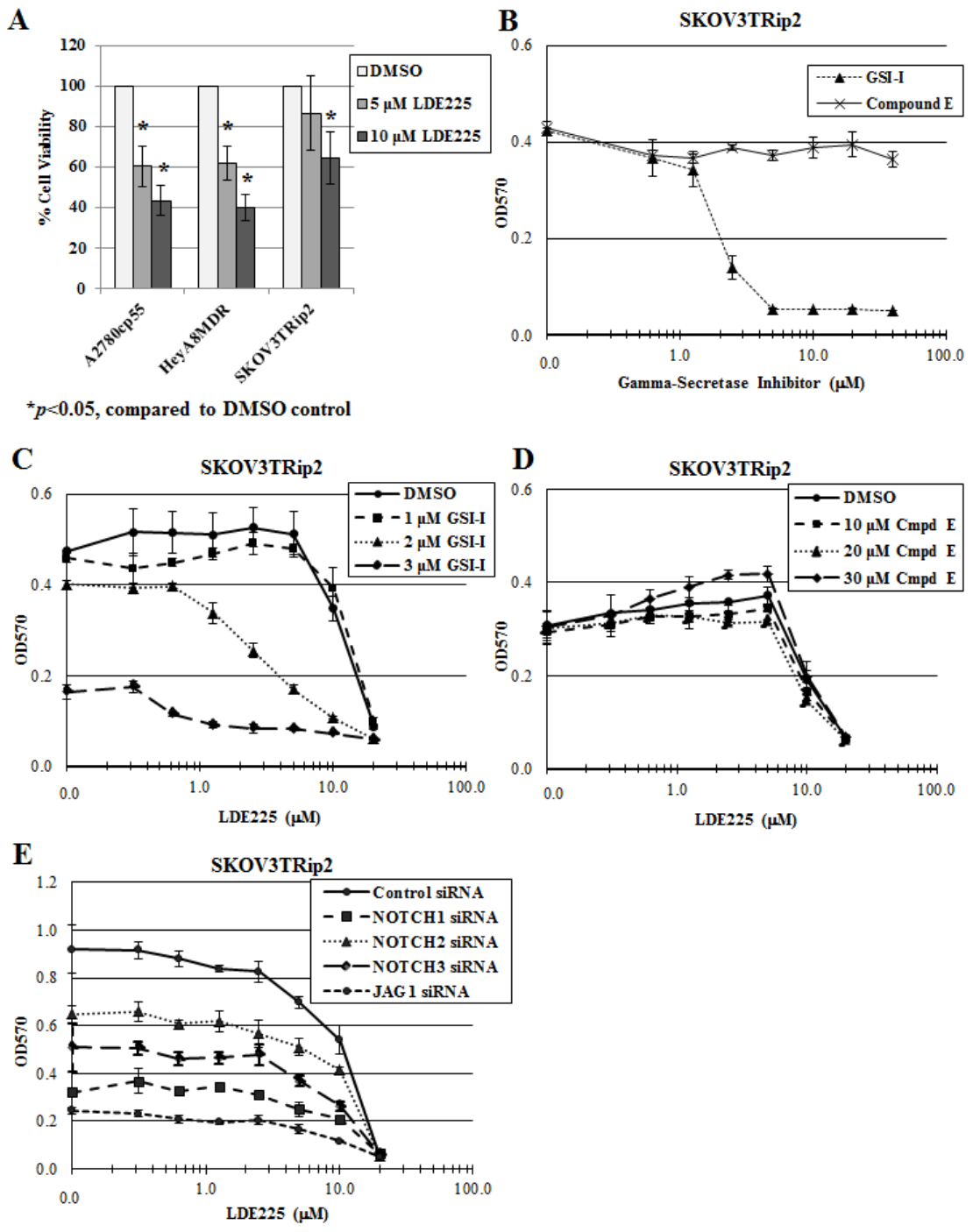

Figure 1: GSI-I, but not Compound E, reverses LDE225 resistance in SKOV3TRip2 cells. A) Cell viability of chemoresistant ovarian cancer cell lines A2780cp55, HeyA8MDR and SKOV3TRip2 following exposure to the Smoothened antagonist, LDE225. B) SKOV3TRip2 cell viability in response to the gamma-secretase inhibitors, GSI-I and Compound E. C) SKOV3TRip2 cell viability following exposure to DMSO or GSI-I combined with increasing concentrations of LDE225. D) SKOV3TRip2 cell viability following exposure to DMSO or Compound E combined with increasing concentrations of LDE225. E) SKOV3TRip2 cell viability following knockdown of Notch signaling components (Notch1, Notch2, Notch3 and Jagged1) in combination with exposure to increasing concentrations of LDE225. In all experiments, cell viability was determined by MTT assay. Data are representative of at least 3 independent experiments. 


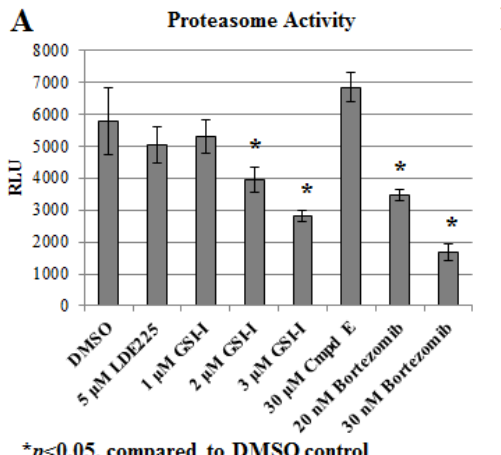

${ }^{\star} p<0.05$, compared to DMSO control

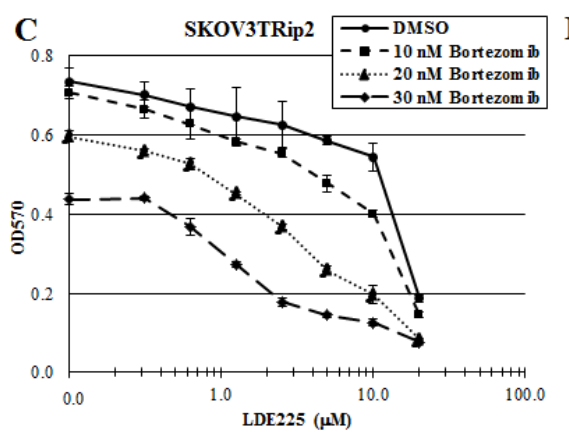

E

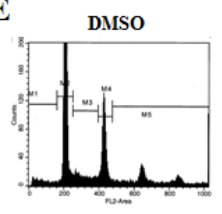

LDE225+GSI-I

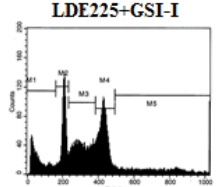

LDE225+Cmpd E F

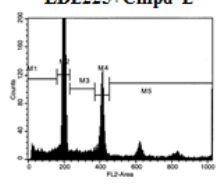

PARP (full-length)

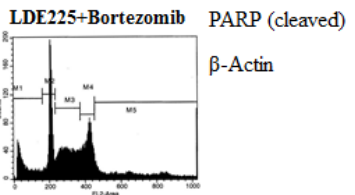

B
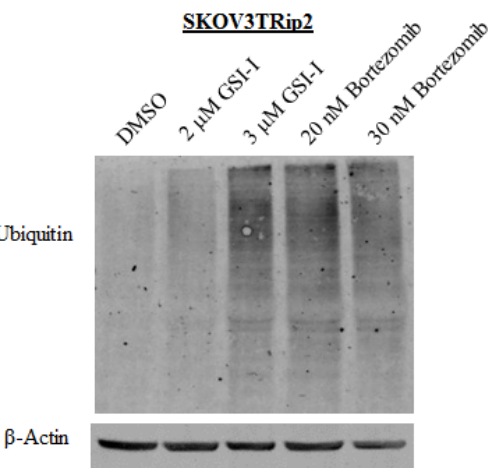

D

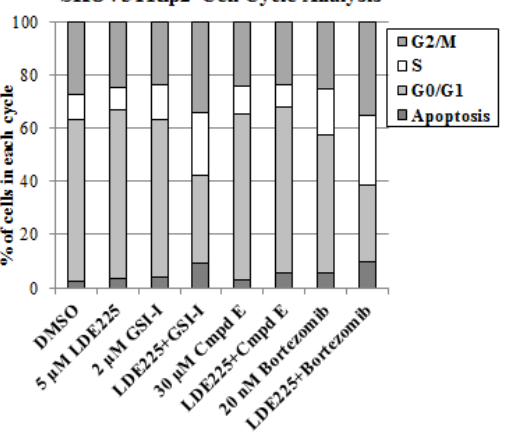

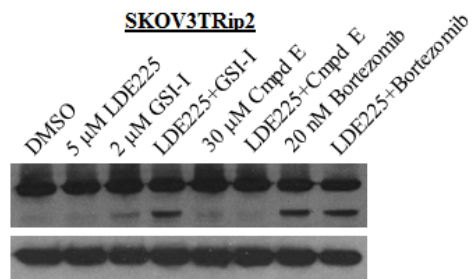

G

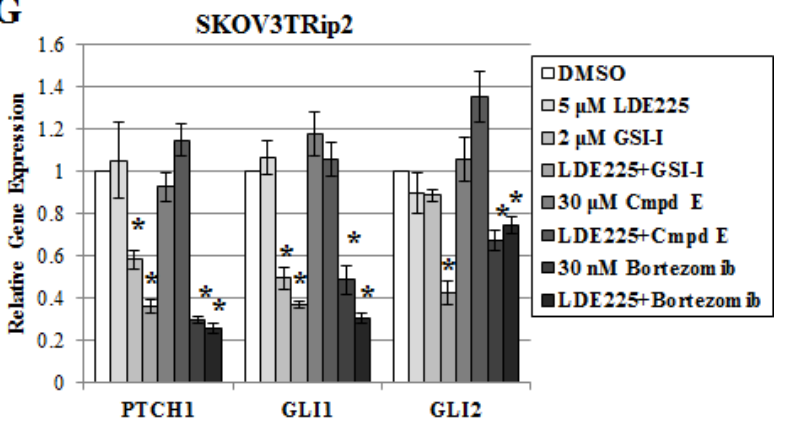

${ }^{\star} p<0.05$, compared to DMSO control

Figure 2: Proteasome inhibition reverses LDE225 resistance in SKOV3TRip2 cells. A) Proteasome activity was measured in SKOV3TRip2 cells exposed to DMSO, LDE225, GSI-I, Compound E or bortezomib at the indicated concentrations for 24 hours. RLU = relative luminescence units. $* P<0.05$, compared to DMSO vehicle control. B) Western blot analysis of ubiquitin was examined in SKOV3TRip2 cells exposed to DMSO, GSI-I or bortezomib overnight to detect the presence of polyubiquitinated proteins. $\beta$-actin was used as a loading control. C) SKOV3TRip2 cell viability following exposure to DMSO or bortezomib combined with increasing concentrations of LDE225, as determined by MTT assay. D) Cell cycle analysis was performed on SKOV3TRip2 cells treated with DMSO alone, LDE225 alone, GSI-I alone, Compound E alone, bortezomib alone, combined LDE225+GSI-I, combined LDE225+Compound E or combined LDE225+bortezomib for 72 hours using propidium iodide (PI) staining. E) Representative histograms of DMSO- and combination-treated cells are shown. F) Protein expression of PARP, an indcator of apoptosis, was examined in SKOV3TRip2 cells treated under the same conditions as those for PI staining using Western blot analysis. $\beta$-actin was used as a loading control. G) Gene expression of PTCH1, GLI1 and GLI2 was examined in SKOV3TRip2 cells treated with DMSO alone, LDE225 alone, GSI-I alone, Compound E alone, bortezomib alone, combined LDE225+GSI-I, combined LDE225+Compound E or combined LDE225+bortezomib for 24 hours. ${ }^{*} P<0.05$, compared to DMSO vehicle control. Data are representative of at least 3 independent experiments. 


\begin{tabular}{|l|l|l|}
\hline Table 1: GSI-Cand bortezomib response in ovarian cancer cellines \\
\hline Cell Line & & \\
\hline A2780ip2 & GSI-I IC $_{50}$ & Bortezomib IC $_{50}$ \\
\hline A2780cp20 & $1.8 \mu \mathrm{M}$ & $7 \mathrm{nM}$ \\
\hline A2780cp55 & $1.7 \mu \mathrm{M}$ & $12.5 \mathrm{nM}$ \\
\hline SKOV3ip1 & $2.9 \mu \mathrm{M}$ & $8.5 \mathrm{nM}$ \\
\hline SKOV3TRip2 & $1.2 \mu \mathrm{M}$ & $6 \mathrm{nM}$ \\
\hline HeyA8 & $3.1 \mu \mathrm{M}$ & $30 \mathrm{nM}$ \\
\hline HeyA8MDR & $2 \mu \mathrm{M}$ & $12 \mathrm{nM}$ \\
\hline ES2 & $1.4 \mu \mathrm{M}$ & $9.5 \mathrm{nM}$ \\
\hline OvCar3 & $1.6 \mu \mathrm{M}$ & $3 \mathrm{nM}$ \\
\hline & $0.6 \mu \mathrm{M}$ & $1.5 \mathrm{nM}$ \\
\hline
\end{tabular}

with GSI-I. Up to a 10-fold decrease in the LDE225 IC50 compared to DMSO control $(\mathrm{CI}=0.64$ at $20 \mathrm{nM}, \mathrm{CI}=0.38$ at $30 \mathrm{nM}$ ) was observed (Figure 2C).

To determine how proteasome inhibition combined with LDE225 might affect cell growth, we performed cell cycle analysis on SKOV3TRip2 cells that were treated with DMSO control, LDE225 $(5 \mu \mathrm{M})$, GSI-I $(2 \mu \mathrm{M})$, Compound E $(30 \mu \mathrm{M})$, bortezomib $(20 \mathrm{nM})$, or combined LDE225+GSI-I, combined LDE225+Compound E or combined LDE225+bortezomib for 72 hours. As shown in Figure 2D, LDE225+GSI-I and LDE225+bortezomib treatment combinations resulted in a greater accumulation of cells in the sub-G0/apoptotic $(9.0 \%$ and $9.5 \%$, respectively, versus $2.5 \%$ control), S ( $23.3 \%$ and $26.1 \%$, respectively, versus $9.9 \%$ control) and G2/M (34.3\% and $35.2 \%$, respectively, versus $27.2 \%$ control) phases compared to DMSO control or either treatment alone (all $\mathrm{p}<0.05$ ). Combined LDE225+Compound E did not have these effects. Representative flow cytometric graphs for combination therapy compared to control are shown in Figure 2E. In addition, poly (ADP-ribose) polymerase (PARP) cleavage, an indicator of apoptosis, was observed in SKOV3TRip2 cells treated with combined LDE225+GSI-I, bortezomib alone and combined LDE225+bortezomib (Figure 2F). These data suggest that the synergy between LDE225 combined with GSI-I or bortezomib results from cell cycle arrest at the $\mathrm{S}$ and G2/M phases, with the induction of apoptosis possibly playing a limited role.

To further examine the mechanism by which proteasome inhibition increases LDE225 sensitivity, we quantified gene expression of PTCH1, GLII and GLI2, established markers of hedgehog pathway activity [36] in SKOV3TRip2 cells exposed to DMSO, LDE225 (5 $\mu \mathrm{M})$, GSI-I $(2 \mu \mathrm{M})$, Compound E $(30 \mu \mathrm{M})$, bortezomib (30 nM), LDE225+GSI-I, LDE225+Compound E or LDE225+bortezomib after 24 hours using qPCR analysis. As shown in Figure 2G, LDE225-resistant SKOV3TRip2 cells demonstrated no significant decrease in PTCH1, GLI1 or GLI2 expression following exposure to single agent LDE225 $(5 \mu \mathrm{M})$. This result agrees with LDE225's lack of an effect on SKOV3TRip2 cell viability at this concentration (see Figure 1A). Surprisingly, GSI-I alone, but again not Compound $\mathrm{E}$, led to a profound decrease in expression of PTCH1 (by $41.8 \%, \mathrm{p}<0.05$ ) and GLI1 (by $50.7 \%, \mathrm{p}<0.05)$ compared to DMSO control. Moreover, combined GSI-I and LDE225 further decreased expression of PTCH1, GLI1 and GLI2 (by $64.2 \%, 63.2 \%$ and $57.6 \%$, respectively; $\mathrm{p}<0.05$ ) compared to DMSO control. Similar to GSI-I, bortezomib alone significantly decreased PTCH1, GLI1 and GLI2 expression in SKOV3TRip2 cells (by up to $70.2 \%, 51.6 \%$ and $32.9 \%$, respectively; $\mathrm{p}<0.05$ ) compared to DMSO control. Combined bortezomib and LDE225 further decreased expression of PTCH1 and GLII (by $74.2 \%$ and $69.4 \%$, respectively; $\mathrm{p}<0.05$ ) compared to LDE alone or DMSO control. These data establish a previously-unrecognized direct effect of proteasome inhibition on hedgehog signaling.

\section{Bortezomib decreases hedgehog transcriptional activity in ovarian cancer cell lines in a dose- dependent manner}

As shown in Table 1, OvCar3 and SKOV3TRip2 cells were the most sensitive and resistant, respectively, to GSI-I and bortezomib. Linear regression analysis of GSI-I and bortezomib response (IC50s) across all cell lines revealed a Pearson correlation coefficient (r) of 0.78 , suggesting a similarity in drug response and mechanism of action (i.e. proteasome inhibition). SKOV3TRip2 cells demonstrated an increased resistance to both GSI-I and bortezomib compared to its parental, chemosensitive cell line, SKOV3ip1 (bortezomib viability results shown in Figure 3A). The effect of bortezomib on hedgehog transcriptional activity (as determined by PTCH1, GLII, GLI2 gene expression) in SKOV3TRip2 cells led us to evaluate this compound in other ovarian cancer cell lines. Interestingly, in all of the ovarian cancer cell lines that were examined by qPCR (A2780cp20, A2780cp55, HeyA8MDR, ES2), bortezomib significantly $(p<0.05)$ decreased hedgehog transcriptional activity in a dosedependent manner within 24 hours (Figure 3B-E). These results agree with the reductions in PTCH1, GLII 
and GLI2 expression observed in SKOV3TRip2 cells following bortezomib treatment (Figure 2E), further demonstrating crosstalk between the proteasome and hedgehog signaling pathways.

\section{Bortezomib increases paclitaxel sensitivity in chemoresistant ovarian cancer cells}

We have previously shown that antagonism of the hedgehog pathway, using LDE225 or siRNAs designed against hedgehog signaling components, can reverse taxane resistance in ovarian cancer cells [16]. The

\section{A}

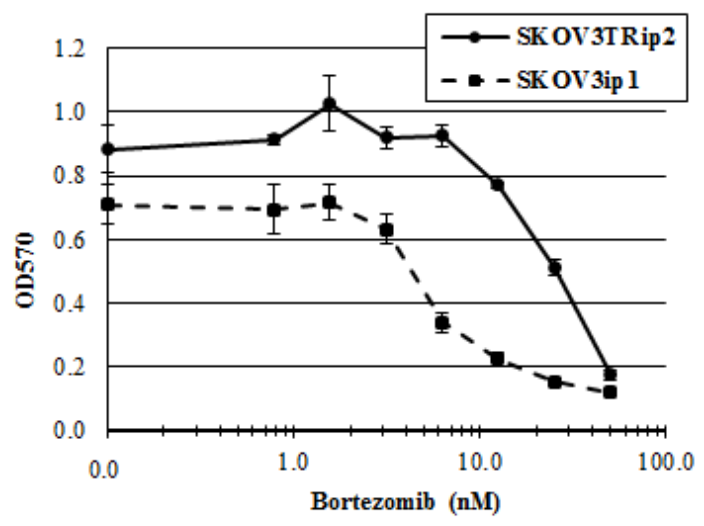

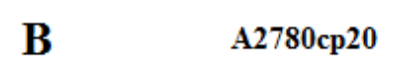
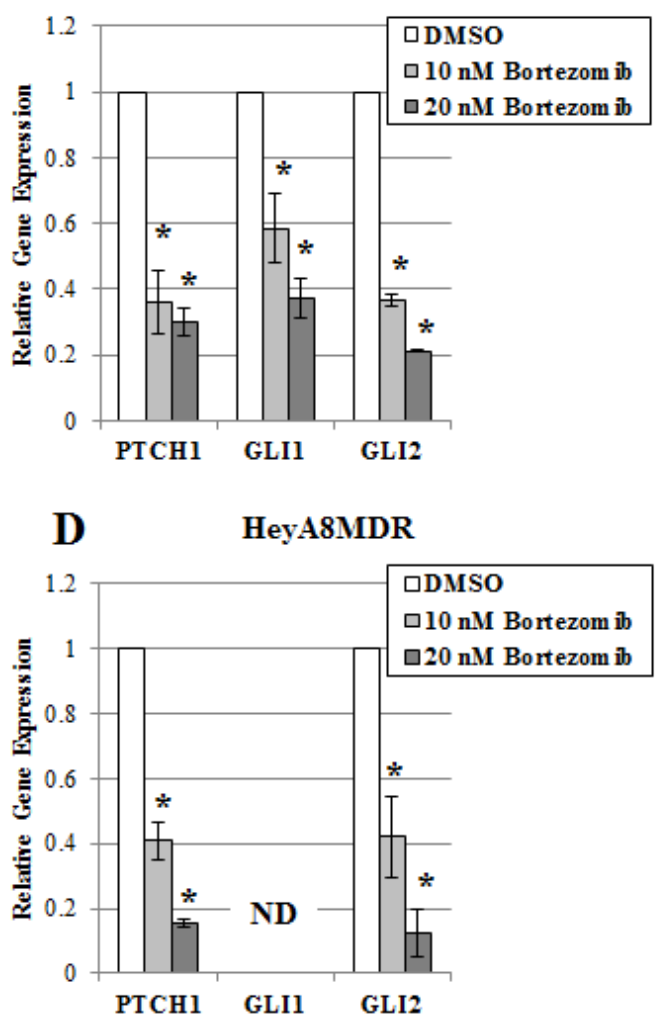

C A2780cp55

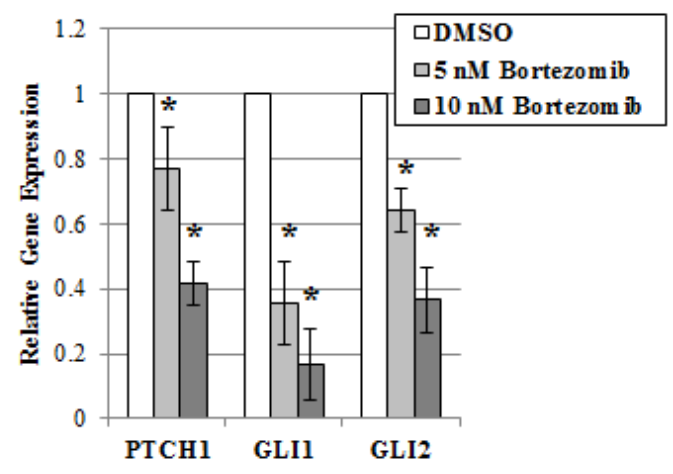

E

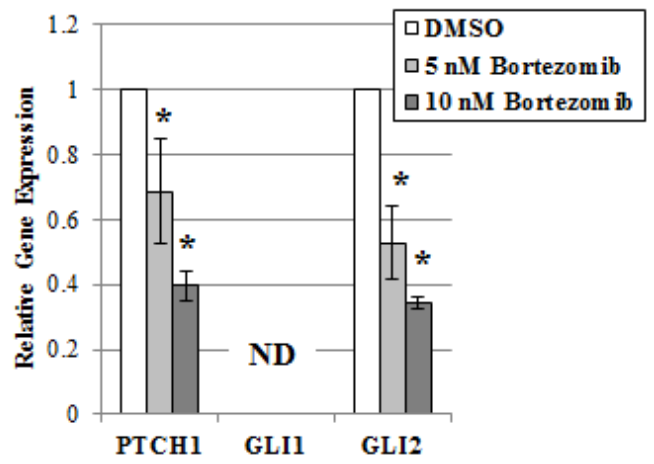

${ }^{\star} p<0.05$, compared to DMSO control

Figure 3: Bortezomib decreases hedgehog transcriptional activity in ovarian cancer cell lines in a dose-dependent manner. A) SKOV3ip1 and SKOV3TRip2 cell viability following exposure to increasing concentrations of bortezomib, as determined by MTT assay. Gene expression of PTCH1, GLI1 and GLI2 was examined in B) A2780cp20, C) A2780cp55, D) HeyA8MDR and E) ES2 ovarian cancer cell lines treated with increasing concentrations of bortezomib for 24 hours, using quantitative PCR. ND = not detectable; $* P<0.05$, compared to DMSO vehicle control. Data are representative of at least 3 independent experiments. 

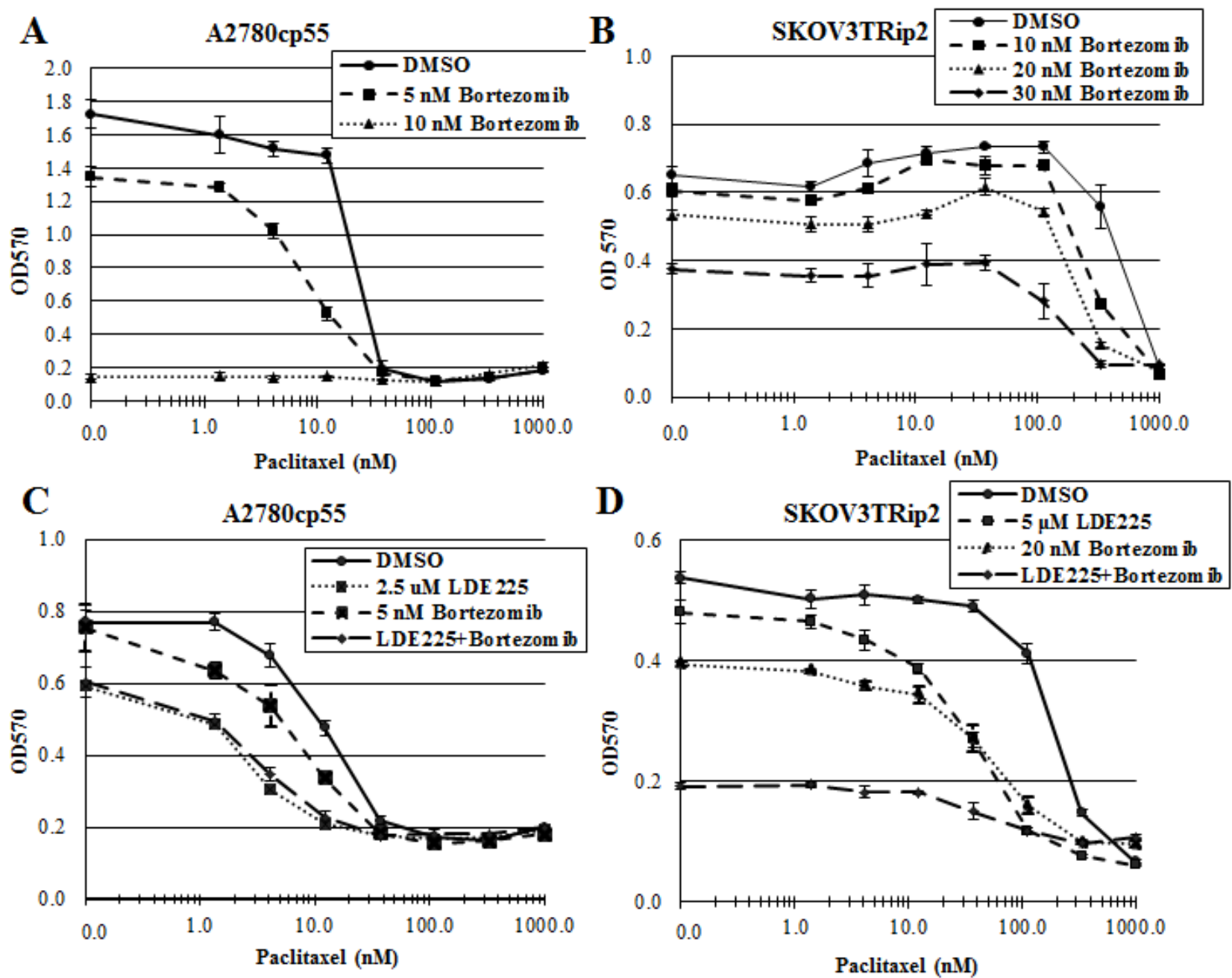

$\mathbf{E}$

\section{$\underline{\text { A2780cp55 }} \quad \underline{\text { SKOV3TRip2 }}$}

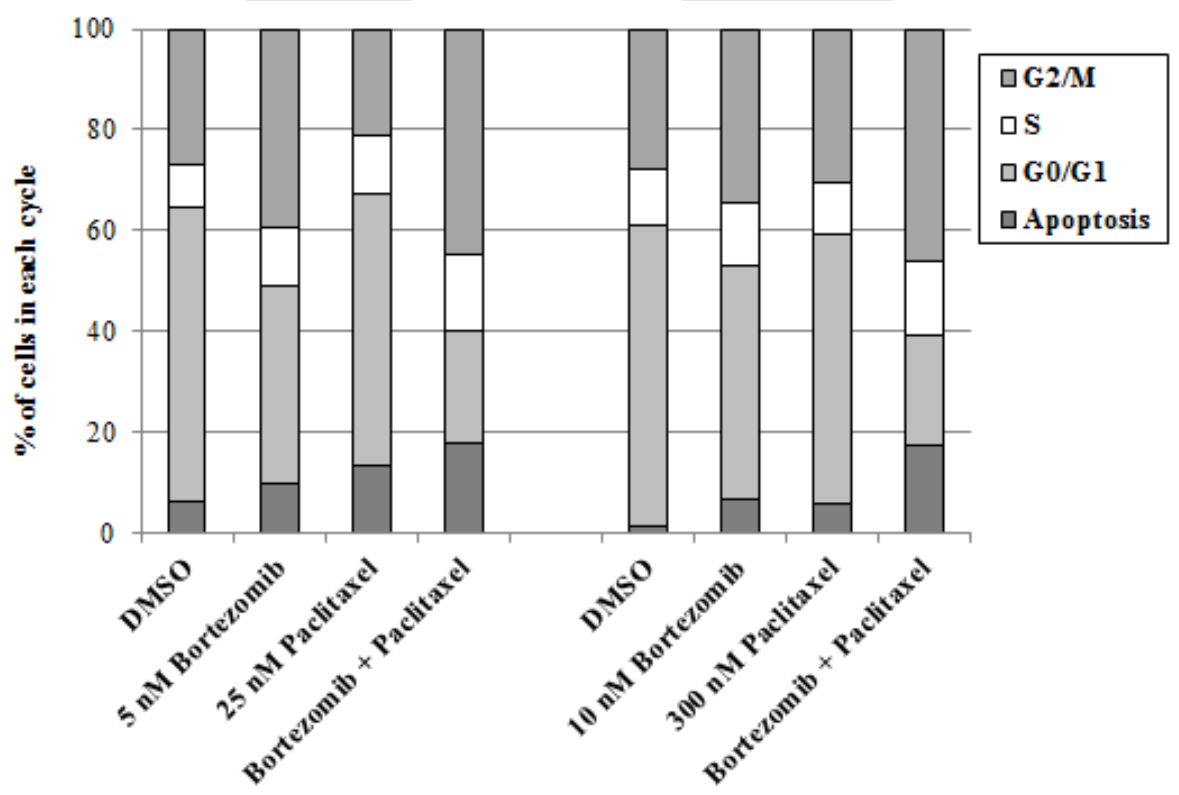




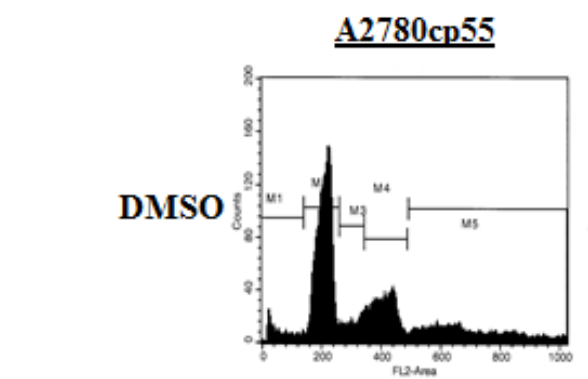

\section{$\underline{\text { SKOV3TRip2 }}$}
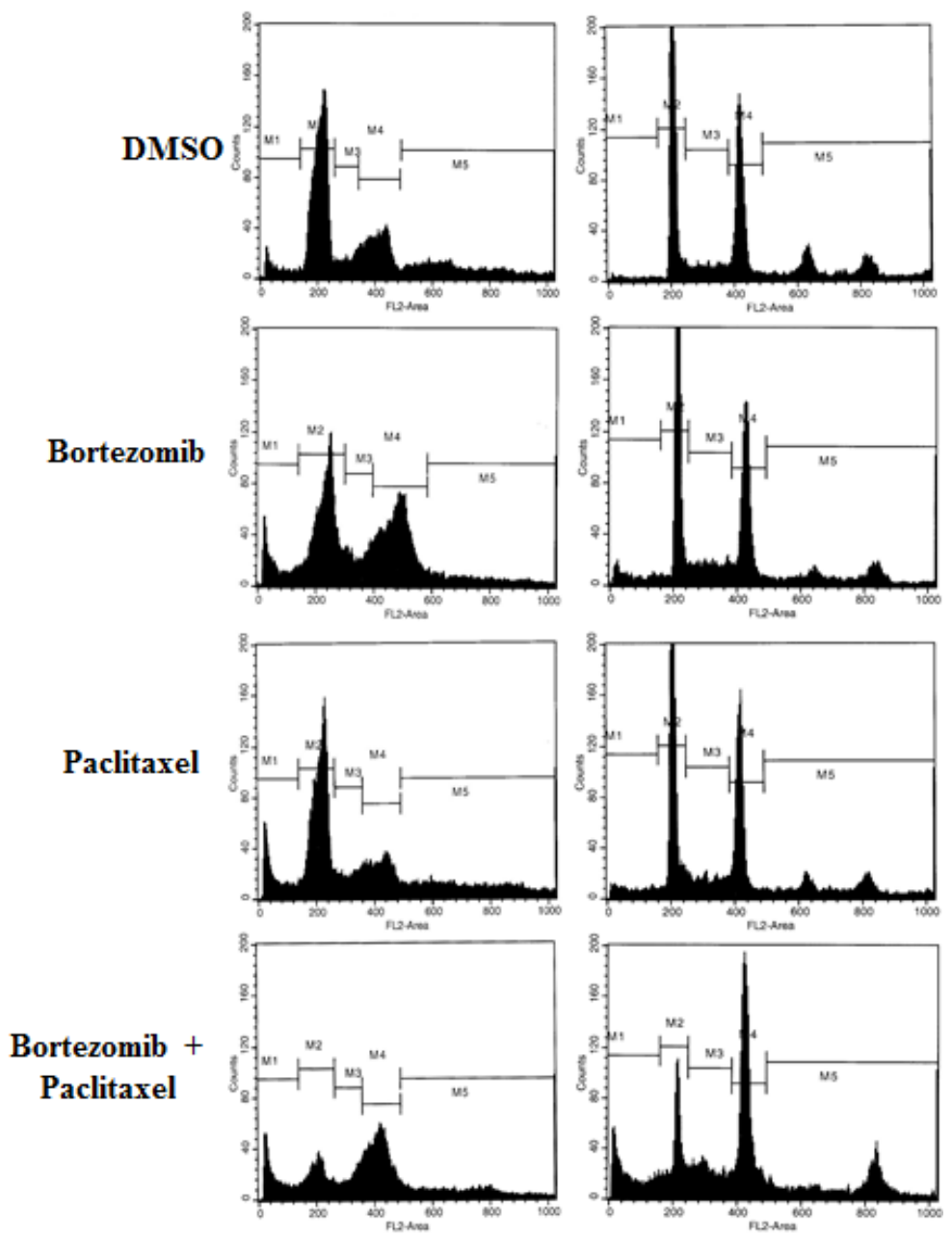

G

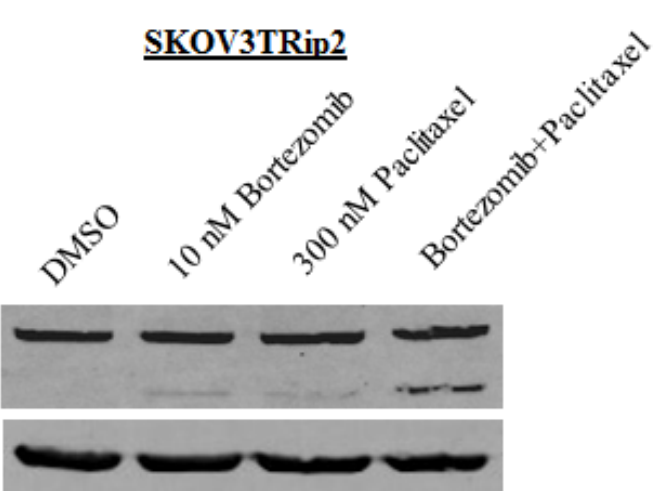

Figure 4: Bortezomib increases paclitaxel sensitivity in chemoresistant ovarian cancer cells. A) A2780cp55 and B) SKOV3TRip2 cell viability following exposure to DMSO or bortezomib combined with increasing concentrations of paclitaxel. C) A2780cp55 and D) SKOV3TRip2 cell viability following treatment with DMSO alone, LDE225 alone, bortezomib alone or LDE225+bortezomib combined with increasing concentrations of paclitaxel. Cell viability was determined using MTT assay. E) Cell cycle analysis was performed on A2780cp55 and SKOV3TRip2 cells treated with DMSO alone, bortezomib alone, paclitaxel alone or combined bortezomib+paclitaxel for 72 hours using propidium iodide (PI) staining. F) Representative histograms of each treatment group in A2780cp55 and SKOV3TRip2 cells are shown. G) Protein expression of PARP, an indcator of apoptosis, was examined in SKOV3TRip2 cells exposed to DMSO alone, bortezomib alone, paclitaxel alone or combined bortezomib+paclitaxel for 72 hours using Western blot analysis. $\beta$-actin was used as a loading control. Data are representative of at least 3 independent experiments. 
inhibitory effect of bortezomib on hedgehog signaling led us to consider whether this compound could be used to increase paclitaxel sensitivity. The chemoresistant ovarian cancer cell lines A2780cp55 and SKOV3TRip2 were exposed to DMSO or bortezomib combined with increasing concentrations of paclitaxel. Interestingly, we found that bortezomib combined with paclitaxel act in a synergistic manner. Up to a 2.3-fold decrease in paclitaxel IC50 compared to DMSO control was observed in $\mathrm{A} 2780 \mathrm{cp} 55$ cells $(\mathrm{CI}=0.47)$ (Figure $4 \mathrm{~A})$ and up to a 2.6-fold decrease in paclitaxel IC50 compared to DMSO control was observed in SKOV3TRip2 cells $(\mathrm{CI}=0.41$ at $30 \mathrm{nM}$ ) (Figure 4B). To determine whether LDE225 combined with bortezomib could have a greater effect on paclitaxel sensitization, we exposed A2780cp55 and SKOV3TRip2 cells to DMSO, LDE225, bortezomib or LDE225+bortezomib combined with increasing concentrations of paclitaxel. In agreement with previous findings [16], LDE225 alone increased the sensitivity of A2780cp55 and SKOV3TRip2 cells to paclitaxel (Figure 4C, D); however, combined LDE225+bortezomib did not further enhance paclitaxel sensitization compared to single agents, indicating an additive effect. These results suggest that bortezomib can sensitize chemoresistant ovarian cancer cells to a similar degree as inhibition of hedgehog signaling.

To determine the mechanism through which bortezomib combined with paclitaxel might affect cell growth in a synergistic manner, we performed cell cycle analysis on A2780cp55 and SKOV3TRip2 cells after treatment with DMSO (vehicle control), bortezomib alone, paclitaxel alone or combined bortezomib+paclitaxel for 72 hours. As shown in Figure 4E/F, bortezomib+paclitaxel combination treatment resulted in a significantly greater $(\mathrm{p}<0.05)$ accumulation of cells in the sub-G0/apoptotic phase $(17.9 \%$ versus $6.2 \%, 9.6 \%, 13.5 \%$ for A2780cp55; $17.1 \%$ versus $1.1 \%, 6.5 \%, 5.8 \%$ for SKOV3TRip2) and the $\mathrm{G} 2 / \mathrm{M}$ phase $(44.9 \%$ versus $27.0 \%, 39.4 \%, 21.3 \%$ for A2780cp55; $46.3 \%$ versus $27.8 \%, 34.6 \%, 30.3 \%$ for SKOV3TRip2) compared to DMSO control, bortezomib alone and paclitaxel alone, respectively. In addition, PARP cleavage was more readily observed in SKOV3TRip2 cells treated with combined bortezomib+paclitaxel compared to DMSO control and single agents (Figure $4 \mathrm{G})$. Taken together, these data suggest that bortezomib, in combination with paclitaxel, induces apoptosis and cell cycle arrest at the $\mathrm{G} 2 / \mathrm{M}$ phase.

\section{Modification of microtubule dynamics plays a role in the sensitization of paclitaxel and LDE225 by bortezomib}

To determine how inhibition of hedgehog signaling by bortezomib could promote increased paclitaxel sensitivity in vitro, we first examined expression of a primary mediator of taxane resistance $A B C B 1 / M D R 1$. This gene encodes for P-glycoprotein, a drug efflux pump that has been shown by our laboratory to play a role in the synergy between LDE225 and paclitaxel [16]. Gene expression of $A B C B 1 / M D R 1$ was measured using qPCR after treatment with increasing concentrations of bortezomib for 72 hours. As shown in Figure 5A, bortezomib $(10,20,30 \mathrm{nM})$ significantly $(\mathrm{p}<0.05)$ decreased $A B C B 1 / M D R 1$ expression in a dose-dependent manner (by $25 \%, 73 \%$ and $83 \%$, respectively), indicating that bortezomib increases paclitaxel sensitivity, at least in part, through inhibition of drug efflux.

To more directly examine the effect of bortezomib on hedgehog signaling and chemotherapy response, we next evaluated the effect of bortezomib on microtubule stabilization. Recent studies have indicated that microtubule dynamics may play a role in bortezomib response [37, 38] as well as hedgehog signaling [39], thereby providing the rationale for examining this cellular process. A2780cp55 cells were treated with DMSO, bortezomib (5 nM), paclitaxel $(50 \mathrm{nM})$ or LDE225 (10 M) for 24 hours, and examined for protein expression of acetylated $\alpha$-tubulin, a marker of microtubule stabilization, using Western blot analysis. Treatment with bortezomib, and to a similar degree with paclitaxel, led to an increase in acetylated $\alpha$-tubulin (Figure 5B). Alternatively, treatment with LDE225 did not have this effect, suggesting that hedgehog inhibition itself does not impact tubulin polymerization. An alternative relationship was hypothesized, whereby hedgehog signaling may actually be a downstream effect of microtubule stabilization. Indeed, A2780cp55 cells treated with microtubulestabilizing agents, paclitaxel and the selective HDAC6 inhibitor, tubastatin-a [40], demonstrated modest but significant $(\mathrm{p}<0.05)$ decreases in GLI1 $(33 \%$ and $30 \%$, respectively) and $G L I 2$ (33\% and $26 \%$, respectively) gene expression (Figure 5C), similar to decreases noted after treatment with bortezomib (Figure 2E, 3B-E). To determine whether microtubule effects play a role in drug sensitization, we exposed chemoresistant ovarian cancer cells to DMSO or tubastatin-a, combined with increasing concentrations of paclitaxel or LDE225. Similar to bortezomib, we found that tubastatin-a increased paclitaxel sensitivity in A2780cp55 cells (up to a 5-fold decrease in IC50 compared to DMSO control; Figure 5D) and in SKOV3TRip2 cells (up to a 3-fold decrease in IC50 compared to DMSO control; Figure 5E). Also similar to bortezomib, tubastatin-a increased LDE225 sensitivity in LDE225-resistant SKOV3TRip2 cells in a dosedependent manner (Figure 5F). Taken together, these data suggest bortezomib can reverse taxane chemoresistance by interfering with microtubule dynamics and, subsequently, hedgehog pathway activity. 
A

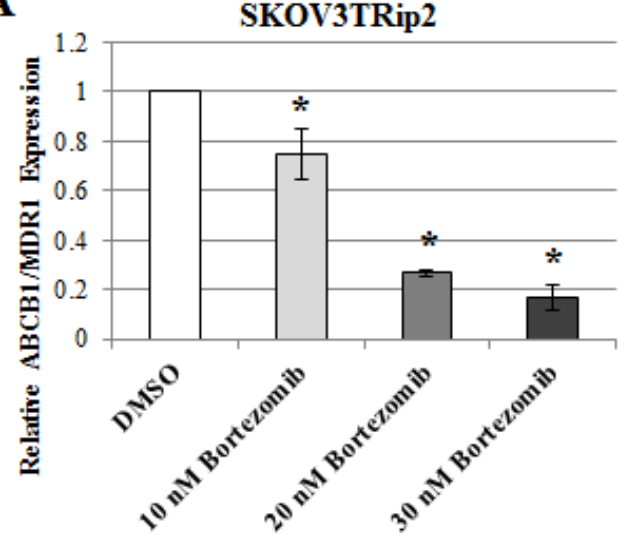

B

Acetyl $\alpha$-tubulin

$\beta$-Actin

\section{$\underline{\mathrm{A} 2780 \mathrm{cp55}}$}

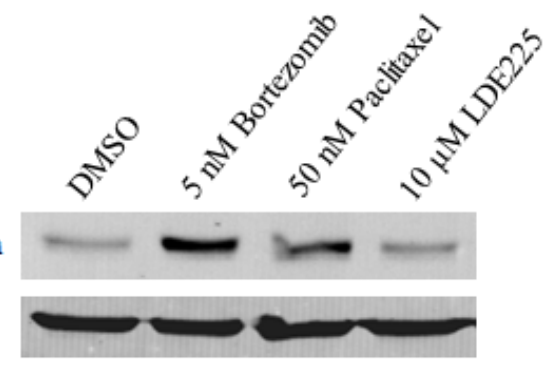

${ }^{*} p<0.05$, compared to DMSO control
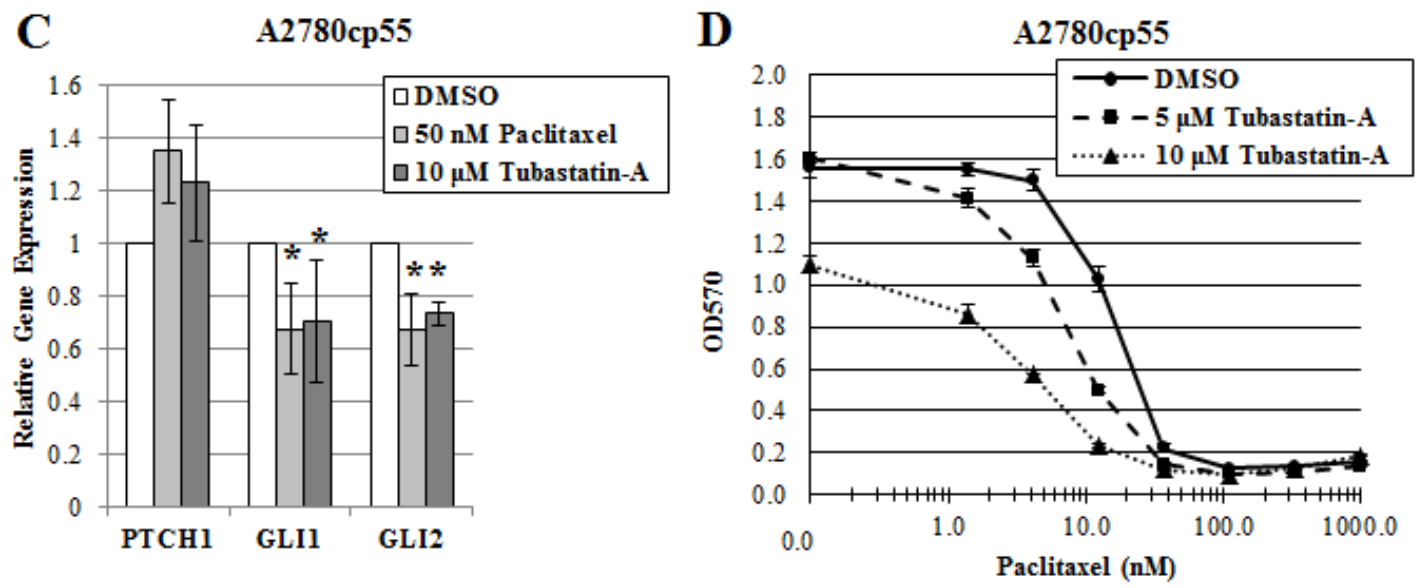

${ }^{\star} p<0.05$, compared to DMSO control

$\mathbf{E}$

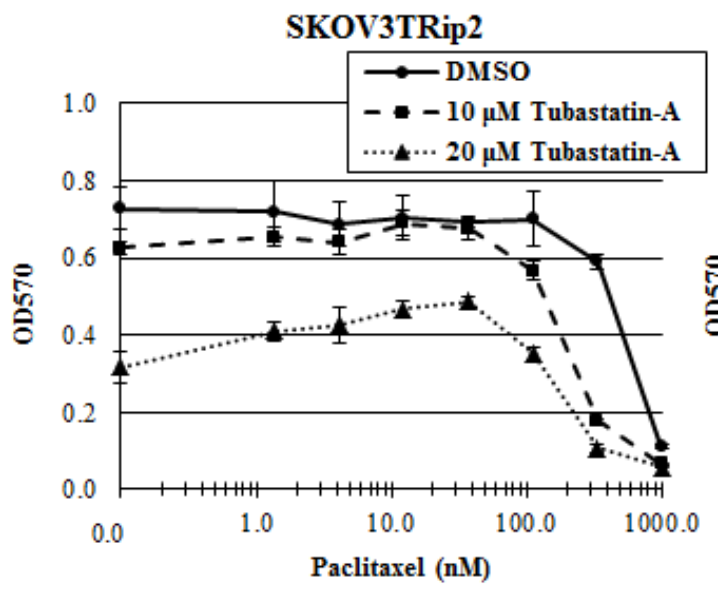

$\mathbf{F}$

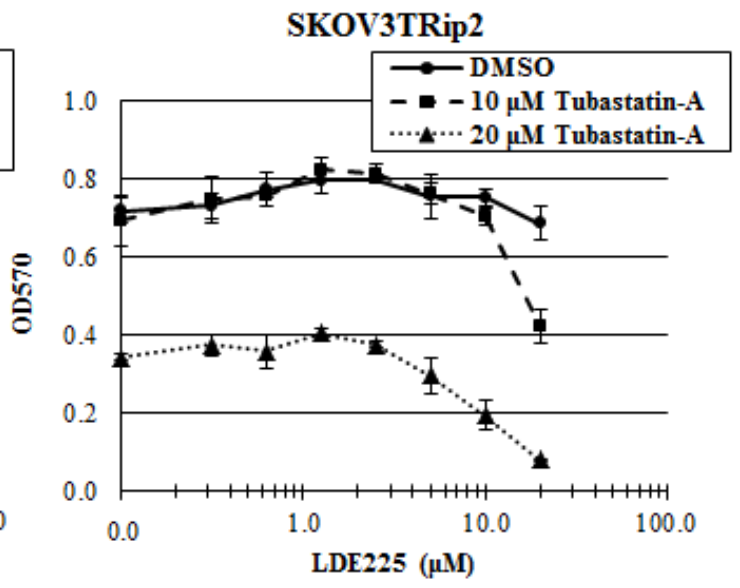

Figure 5: Modification of microtubule dynamics plays a role in the sensitization of paclitaxel and LDE225 by bortezomib. A) Gene expression of $A B C B 1 / M D R 1$ was examined in SKOV3TRip2 cells treated with DMSO or bortezomib at the indicated doses for 72 hours, using quantitative PCR. $* P<0.05$, compared to DMSO vehicle control. B) Protein expression of acetylated $\alpha$-tubulin was examined in A2780cp55 cells treated with DMSO, bortezomib, paclitaxel or LDE225 for 24 hours using Western blot analysis. -actin was used as a loading control. C) Gene expression of PTCH1, GLI1 and GLI2 was examined in A2780cp55 cells treated with DMSO, paclitaxel or tubastatin-a for 24 hours, using quantitative PCR. ${ }^{*} P<0.05$, compared to DMSO vehicle control. D) A2780cp55 and E) SKOV3TRip2 cell viability following exposure to DMSO or tubastatin-a combined with increasing concentrations of paclitaxel. F) SKOV3TRip2 cell viability following treatment with DMSO or tubastatin-a combined with increasing concentrations of LDE225. Cell viability was determined using MTT assay. Data are representative of at least 3 independent experiments. 


\section{DISCUSSION}

In the current study, we found that inhibiting the proteasome, using two distinct pharmacologic agents, decreased hedgehog pathway activity and increased LDE225 sensitivity in an ovarian cancer model. Moreover, proteasome inhibition sensitized chemoresistant ovarian cancer cells to paclitaxel. These effects appear to be mediated, at least in part, by modification of microtubule dynamics within ovarian cancer cells. The participation of proteasome inhibition in reversing chemotherapeutic and targeted therapy resistance makes it an attractive clinical strategy, considering most ovarian cancer patients develop tumor recurrence and succumb to chemoresistant disease.

Recent studies have identified clinical resistance to selective hedgehog antagonists, such as GDC-0449/ vismodegib and LDE225/erismodegib [18-21]; however, strategies for reversing this resistance have not been well defined. In a previous study, we reported that GLII and GLI2 mRNA levels, indicators of hedgehog signaling, were significantly higher in cancer cells isolated from persistent/chemoresistant ovarian tumors compared to those isolated from matched primary tumors [41]. In addition, we have shown that hedgehog signaling plays a role in ovarian cancer chemoresistance [16]. Based on these data, the utility of developing methods for increasing sensitivity to hedgehog antagonists becomes apparent. Initially, we focused on crosstalk between the hedgehog and Notch signaling pathways as a potential mechanism of LDE225 resistance, based upon the finding that the Notch ligand Jagged1 can regulate hedgehog signaling [32]. Inhibition of the gamma-secretase complex, which is essential for processing of the Notch signaling cascade, initially provided contrasting results, as one of the agents, GSI-I, sensitized ovarian cancer cells to LDE225, whereas another agent, GSI-XXI/Compound E, did not. Moreover, knockdown of individual Notch signaling components (Notch1, Notch2, Notch3 and Jagged1) did not increase LDE225 sensitivity, suggesting that Notch/ hedgehog interactions are not involved in resistance to this compound. Since GSI-I, but not Compound E, was found to increase LDE225 sensitivity in ovarian cancer cells, we sought to identify an alternative mechanism of action for GSI-I that is independent of gamma-secretase inhibition. Recent studies have indicated that GSI-I can act as a proteasome inhibitor [33-35], largely due to the fact that this compound is derived from MG132, a known proteasome inhibitor [42]. Evaluation of GSI-I on proteasome activity revealed that this compound does significantly inhibit the proteasome in our ovarian cancer model.

Based on this evidence, we combined the more selective and clinically available proteasome inhibitor, bortezomib, with LDE225 to determine if the same sensitization would result, which we did observe in vitro. GSI-I and bortezomib also similarly increased cell cycle arrest ( $\mathrm{S}$ and $\mathrm{G} 2 / \mathrm{M}$ phases) and apoptosis in combination with LDE225, compared to DMSO control or single agents. It was demonstrated from the qPCR analysis of cells treated with GSI-I or bortezomib that there is crosstalk between the proteasome and hedgehog signaling pathways, as the mRNA levels of hedgehog target genes (PTCH1, GLI1 and GLI2) decrease with exposure to either drug. It has been proposed that hedgehog inhibitor resistance may be due to three distinct mechanisms: 1) mutations within Smoothened that prevent molecular interaction with the inhibitor, 2) activation of compensatory pathways, 3) increased amplification of downstream mediators in the hedgehog pathway, such as the Gli transcription factors $[18,20]$. If resistance to LDE225 is occurring upstream (perhaps at the level of Smoothened), it could be theorized that suppression of hedgehog signaling downstream of Smoothened (through proteasome inhibition) would help alleviate this resistance.

Based on our previous finding that hedgehog antagonism could be used to reverse taxane resistance [16], we asked whether proteasome inhibition, through its effect on hedgehog, could be used to achieve the same goal. Indeed, we found that bortezomib sensitized chemoresistant ovarian cancer cells to paclitaxel. This combination effect was accompanied by decreased expression of $A B C B 1 / M D R 1$, a drug efflux pump that is strongly associated with taxane resistance and hedgehog pathway upregulation $[14,16]$. Having found that bortezomib was able to increase sensitivity to LDE225 and paclitaxel in vitro, we sought to identify a common mechanism that could account for these biologic effects. Recent studies have implicated microtubule stabilization as one of bortezomib's mechanisms of action [37, 38]. In addition, microtubule dynamics have been shown to play a role in regulating hedgehog signaling [39]. These studies led us to investigate the impact of bortezomib on microtubule function. In agreement with microtubulestabilizing agents, bortezomib alone, and in combination with paclitaxel, was found to induce G2/M phase arrest. Moreover, bortezomib increased acetylation of $\alpha$-tubulin, a marker of microtubule stabilization and HDAC6 inhibition [43], compared to DMSO control. As single agents, the microtubule stabilizing agents, paclitaxel and the selective HDAC6 inhibitor, tubastatin-a, decreased hedgehog gene expression, suggesting that the changes in microtubule dynamics following bortezomib treatment are associated with decreases in hedgehog signaling. LDE225 did not affect acetylated $\alpha$-tubulin, indicating that hedgehog inhibition itself is not responsible for microtubule stabilization, but rather occurs downstream of this event. Sensitization of chemoresistant ovarian cancer cells to paclitaxel and LDE225 by tubastatin-a further suggests that microtubule effects are a mechanism whereby bortezomib can induce chemosensitivity.

Because bortezomib and paclitaxel seem to share a common mechanism of action (i.e. microtubule 
stabilization), it would seem counterintuitive for these agents to act in a synergistic manner when combined. The same could be said of the combination effects of tubastatin-a and paclitaxel. As suggested by Poruchynsky et al. [37], it could be postulated that proteasome inhibition increases the expression of proteins that help stabilize microtubules, thereby providing a favorable environment for paclitaxel effects. In addition, HDAC6 may play a role in regulating these microtubule-associated proteins or vice versa, thereby affecting microtubule dynamics in a manner independent of the mechanism by which paclitaxel causes microtubule stabilization, which is through direct binding to tubulin [44]. In terms of LDE225 sensitization, it could be additionally inferred that HDAC6 inhibition results in decreased hedgehog signaling downstream of Smoothened, thereby overcoming potential resistance mechanisms that exist at the level of this receptor or compensatory pathways.

Collectively, this study validates proteasome inhibition as a strategy for reversing resistance to chemotherapy and hedgehog-targeting agents in an ovarian cancer model. With the ability to identify cancer patients whose tumors have active hedgehog signaling, proteasome inhibition could ultimately provide a useful therapeutic strategy for reversing chemoresistance and increasing overall survival in ovarian cancer patients.

\section{METHODS}

\section{Reagents and cell culture}

LDE225 was kindly provided by Novartis Pharma AG (Basel, Switzerland) and dissolved in DMSO to create a $10 \mathrm{mM}$ stock solution. Gamma-secretase inhibitor I (GSI-I; Calbiochem, Billerica, MA) and gammasecretase inhibitor XXI (Compound E; Calbiochem) were each dissolved in DMSO to create $4 \mathrm{mM}$ stock solutions. Bortezomib (Selleckchem, Houston, TX) was dissolved in DMSO to prepare a $10 \mathrm{mM}$ stock solution. Tubastatin-A (Sigma-Aldrich, St. Louis, MO), a kind gift of Dr. Douglas R. Hurst, was dissolved in DMSO to prepare a $5 \mathrm{mg} / \mathrm{ml}(13.5 \mathrm{mM})$ stock solution. The ovarian cancer cell lines A2780ip2, A2780cp20, A2780cp55, ES2, HeyA8, HeyA8MDR, OvCar3, SKOV3ip1 and SKOV3TRip2 were maintained in RPMI-1640 medium supplemented with 10\% fetal bovine serum (Hyclone, Logan, UT). A2780cp20 and A2780cp55 (platinum- and taxane-resistant), HeyA8MDR (taxane-resistant) and SKOV3TRip2 (taxane-resistant, a kind gift of Dr. Michael Seiden [45]) were generated by sequential exposure to increasing concentrations of chemotherapy [46]. HeyA8MDR and SKOV3TRip2 were maintained with the addition of $150 \mathrm{ng} / \mathrm{ml}$ of paclitaxel. All cell lines were routinely screened for Mycoplasma species (GenProbe detection kit; Fisher, Itasca, IL) with experiments performed at $70-80 \%$ confluent cultures. Purity of cell lines was confirmed with STR genomic analysis, and only cells less than 20 passages from stocks were used in experiments.

\section{Cell viability assays}

In each well of a 96-well plate, 2,000 cells were exposed to increasing concentrations of single agents, in triplicate. For combination studies, cells were treated with fixed doses of GSI-I, Compound E, bortezomib or tubastatin-a combined with increasing concentrations of LDE225, in triplicate. In addition, cells were exposed to fixed doses of bortezomib, tubastatin-a, LDE225 or LDE225+bortezomib combined with increasing concentrations of paclitaxel, in triplicate. For combination studies, all drugs were added at the same time and cells were allowed to grow until the control groups reached $80-90 \%$ confluency (usually 72 hours). After this time, $50 \mu \mathrm{L}$ of $0.15 \%$ MTT dye (Sigma-Aldrich) was added to each well and the plate was incubated at $37^{\circ} \mathrm{C}$ for 2 hours. Conversion of MTT to formazan, a measure of cell viability, was determined using an Epoch Microplate Spectrophotometer (BioTek, Winooski, VT). IC50 of the drug of interest was determined by finding the dose at which $50 \%$ inhibition of cell viability was achieved, calculated by the equation $\left[\left(\mathrm{OD} 570_{\mathrm{MAX}}-\mathrm{OD} 570_{\mathrm{MIN}}\right) / 2\right)+$ OD570 ${ }_{\mathrm{MIN}}$ ].

\section{siRNA transfection}

To examine the effect of Notch1, Notch2, Notch3 or Jagged1 knockdown on LDE225 response in vitro, SKOV3TRip2 cells were exposed to control siRNA (target sequence: 5'-UUCUCCGAACGUGUCACGU-3', Sigma-Aldrich), NOTCH1-targeting siRNA (5'-GUGUGAAUCCAACCCUUGU-3', Sigma-Aldrich), NOTCH2-targeting siRNA (5'-CUGUCAUACCCUCUUGUGU-3', Sigma-Aldrich), NOTCH3-targeting siRNA (5'-GGUAGUAAUGCUGGAGAUU-3',

Sigma-Aldrich) or JAG1-targeting siRNA (5'-CCUGUAACAUAGCCCGAAA-3', Sigma-Aldrich) at a 1:3 siRNA $(\mu \mathrm{g})$ to Lipofectamine 2000 (Invitrogen, Carlsbad, CA) $(\mu \mathrm{L})$ ratio. These siRNAs have previously been validated as having decreased the mRNA and protein levels of their respective target [32]. Cells were first transfected with siRNA $(5 \mu \mathrm{g})$ overnight in 6-well plates $(250,000$ cells/well), then trypsinized and re-plated at 2,000 cells per well on a 96-well plate, followed by addition of increasing concentrations of LDE225 after attachment. Cell viability was then assessed by MTT assay. 


\section{Proteasome activity assay}

SKOV3Trip2 cells were plated in white-walled 96well plates (2,000 cells/well), allowed to attach overnight, and exposed to DMSO, LDE225, GSI-I, Compound E or bortezomib, in quadruplicate, at the indicated doses for 24 hours. Proteasome activity was measured in these treated cells using the Proteasome-Glo ChymotrypsinLike Cell-Based Assay kit (Promega, Madison, WI). One hundred $\mu 1$ of Proteasome-Glo reagent was added to the $100 \mu 1$ of media present in each well, mixed for 2 minutes at $700 \mathrm{rpm}$ using a plate shaker and incubated at room temperature for 2 hours. Luminescence was measured in each well using a Synergy HT Microplate Reader (Biotek).

\section{Cell cycle analysis}

Cells were treated with the indicated agents for 72 hours, trypsinized, and fixed in $100 \%$ ethanol overnight at $4^{\circ} \mathrm{C}$. Cells were then centrifuged, washed in PBS, and resuspended in PBS containing 0.1\% Triton X-100 (v/v), $200 \mu \mathrm{g} / \mathrm{mL}$ DNase-free RNase A and $20 \mu \mathrm{g} / \mathrm{mL}$ propidium iodide (PI). Cells were incubated in the PI staining solution for at least 30 minutes at $4^{\circ} \mathrm{C}$ prior to analysis. PI fluorescence was assessed by flow cytometry and the percentage of cells in sub-G0, G0/G1, S and G2/M phases was calculated by the cell cycle analysis module for Flow Cytometry Analysis Software (FlowJo v.7.6.1, Ashland, OR).

\section{RNA extraction and reverse transcription}

Total RNA was isolated from ovarian cancer cell lines using Trizol reagent (Invitrogen) per manufacturer's instructions. RNA was then DNase treated and purified using the RNeasy Mini Kit (QIAGEN, Hilden, Germany). RNA was eluted in $50 \mu \mathrm{L}$ of RNase-free water and stored at $-80^{\circ} \mathrm{C}$. The concentration of all RNA samples was quantified by spectrophotometric absorbance at 260/280 $\mathrm{nm}$ using a Take3 Micro-Volume Plate in an Epoch Microplate Spectrophotometer (BioTek). Prior to cDNA synthesis, all RNA samples were diluted to $20 \mathrm{ng} / \mu \mathrm{L}$ using RNase-free water. cDNA was prepared using the High Capacity cDNA Reverse Transcription Kit (Applied Biosystems, Foster City, CA). The resulting cDNA samples were analyzed using quantitative PCR.

\section{Quantitative PCR}

Primer and probe sets for GLII (Hs00171790 $\mathrm{m} 1), \quad$ GLI2 (Hs00257977_m1), ABCB1/MDR $\overline{1}$ (Hs00184500_m1), PTCH1 (Hs00181117_m1) and RPLPO (Hs99999902_m1; housekeeping gene) were obtained from Applied Biosystems and used according to manufacturer's instructions. PCR amplification was performed on an ABI Prism 7900HT sequence detection system and gene expression was calculated using the comparative $\mathrm{C}_{\mathrm{T}}$ method as previously described [47] Briefly, this technique uses the formula $2^{-\Delta \Delta C}$ to calculate the expression of target genes normalized to a calibrator. The cycling threshold $\left(\mathrm{C}_{\mathrm{T}}\right)$ indicates the cycle number at which the amount of amplified target reaches a fixed threshold. $\mathrm{C}_{\mathrm{T}}$ values range from 0 to 40 (the latter representing the default upper limit PCR cycle number that defines failure to detect a signal).

\section{Western blot analysis}

Cell lysates were collected in modified radioimmunoprecipitation assay (RIPA) lysis buffer with protease inhibitor cocktail (Roche, Manheim, Germany). Lysates were subjected to immunoblot analysis by standard techniques [46] using ubiquitin antibody (P4D1, Cell Signaling Technology, Danvers, MA), poly (ADP-ribose) polymerase (PARP) antibody (7D3-6, BD Pharmingen, San Jose, CA), or acetylated $\alpha$-tubulin antibody (D20G3, Cell Signaling Technology) at 1:1000 dilution overnight at $4^{\circ} \mathrm{C}$ or anti- $\beta$-actin antibody (AC15, Sigma-Aldrich) at 1:10,000 dilution for 1 hour at RT, which was used to monitor equal sample loading. After washing, blots were incubated with goat anti-rabbit (for acetylated $\alpha$-tubulin) or goat anti-mouse (for ubiquitin, PARP, $\beta$-actin) secondary antibodies (Bio-Rad, Hercules, CA) conjugated with horseradish peroxidase. Visualization was performed by the enhanced chemiluminescence method (Pierce Thermo Scientific, Rockford, IL).

\section{Statistical analysis}

Comparisons of cell viability, gene expression, relative luminescence units (RLU), and PI fluorescence were analyzed using a two-tailed Student's t-test, if assumptions of data normality were met. Those represented by alternate distribution were examined using a nonparametric Mann-Whitney $U$ test. In the case of multiple group comparisons, one-way analysis of variance (ANOVA) followed by Tukey's post-test was performed. Differences between groups were considered statistically significant at $\mathrm{p}<0.05$. Error bars represent standard deviation unless otherwise stated. The combination index (CI) method [48] was used to identify synergistic interactions between different compounds in their effect on cancer cell viability. A CI value equal to 1 indicates an additive effect, a CI value less than 1 indicates synergy (greater than additive) and a CI value greater than 1 indicates antagonism. 


\section{ACKNOWLEDGEMENTS}

Funding support provided in part by the University of Alabama at Birmingham Center for Clinical and Translational Science (5UL1RR025777) and the Department of Defense Ovarian Cancer Research Academy (OC093443).

\section{REFERENCES}

1. Bhoola S and Hoskins WJ. Diagnosis and management of epithelial ovarian cancer. Obstet Gynecol. 2006; 107(6):1399-1410.

2. Wang Z, Li Y, Banerjee S and Sarkar FH. Emerging role of Notch in stem cells and cancer. Cancer letters. 2009; 279(1):8-12.

3. Pasca di Magliano M and Hebrok M. Hedgehog signalling in cancer formation and maintenance. Nature reviews Cancer. 2003; 3(12):903-911.

4. Theunissen JW and de Sauvage FJ. Paracrine Hedgehog signaling in cancer. Cancer research. 2009; 69(15):60076010 .

5. Hopfer O, Zwahlen D, Fey MF and Aebi S. The Notch pathway in ovarian carcinomas and adenomas. British journal of cancer. 2005; 93(6):709-718.

6. Park JT, Li M, Nakayama K, Mao TL, Davidson B, Zhang Z, Kurman RJ, Eberhart CG, Shih Ie M and Wang TL. Notch3 gene amplification in ovarian cancer. Cancer research. 2006; 66(12):6312-6318.

7. Choi JH, Park JT, Davidson B, Morin PJ, Shih Ie M and Wang TL. Jagged-1 and Notch3 juxtacrine loop regulates ovarian tumor growth and adhesion. Cancer research. 2008; 68(14):5716-5723.

8. Jung SG, Kwon YD, Song JA, Back MJ, Lee SY, Lee C, Hwang YY and An HJ. Prognostic significance of Notch 3 gene expression in ovarian serous carcinoma. Cancer science. 2010; 101(9):1977-1983.

9. Chen X, Horiuchi A, Kikuchi N, Osada R, Yoshida J, Shiozawa $\mathrm{T}$ and Konishi I. Hedgehog signal pathway is activated in ovarian carcinomas, correlating with cell proliferation: it's inhibition leads to growth suppression and apoptosis. Cancer science. 2007; 98(1):68-76.

10. Bhattacharya R, Kwon J, Ali B, Wang E, Patra S, Shridhar $\mathrm{V}$ and Mukherjee $\mathrm{P}$. Role of hedgehog signaling in ovarian cancer. Clinical cancer research : an official journal of the American Association for Cancer Research. 2008; 14(23):7659-7666.

11. Liao X, Siu MK, Au CW, Wong ES, Chan HY, Ip PP, Ngan HY and Cheung AN. Aberrant activation of hedgehog signaling pathway in ovarian cancers: effect on prognosis, cell invasion and differentiation. Carcinogenesis. 2009; 30(1):131-140.

12. Zhang S, Balch C, Chan MW, Lai HC, Matei D, Schilder JM, Yan PS, Huang TH and Nephew KP. Identification and characterization of ovarian cancer-initiating cells from primary human tumors. Cancer research. 2008; 68(11):4311-4320.

13. Park JT, Chen X, Trope CG, Davidson B, Shih Ie M and Wang TL. Notch3 overexpression is related to the recurrence of ovarian cancer and confers resistance to carboplatin. The American journal of pathology. 2010; 177(3):1087-1094.

14. Sims-Mourtada J, Izzo JG, Ajani J and Chao KS. Sonic Hedgehog promotes multiple drug resistance by regulation of drug transport. Oncogene. 2007; 26(38):5674-5679.

15. Singh RR, Kunkalla K, Qu C, Schlette E, Neelapu SS, Samaniego F and Vega F. ABCG2 is a direct transcriptional target of hedgehog signaling and involved in stromainduced drug tolerance in diffuse large B-cell lymphoma. Oncogene. 2011; 30(49):4874-4886.

16. Steg AD, Katre AA, Bevis KS, Ziebarth A, Dobbin ZC, Shah MM, Alvarez RD and Landen CN. Smoothened antagonists reverse taxane resistance in ovarian cancer. Molecular cancer therapeutics. 2012; 11(7):1587-1597.

17. Fortini ME. Notch signaling: the core pathway and its posttranslational regulation. Developmental cell. 2009; 16(5):633-647.

18. Metcalfe $\mathrm{C}$ and de Sauvage FJ. Hedgehog fights back: mechanisms of acquired resistance against Smoothened antagonists. Cancer research. 2011; 71(15):5057-5061.

19. Yauch RL, Dijkgraaf GJ, Alicke B, Januario T, Ahn CP, Holcomb T, Pujara K, Stinson J, Callahan CA, Tang T, Bazan JF, Kan Z, Seshagiri S, Hann CL, Gould SE, Low JA, et al. Smoothened mutation confers resistance to a Hedgehog pathway inhibitor in medulloblastoma. Science. 2009; 326(5952):572-574.

20. Buonamici S, Williams J, Morrissey M, Wang A, Guo R, Vattay A, Hsiao K, Yuan J, Green J, Ospina B, Yu Q, Ostrom L, Fordjour P, Anderson DL, Monahan $\mathrm{JE}$, Kelleher JF, et al. Interfering with resistance to smoothened antagonists by inhibition of the PI3K pathway in medulloblastoma. Science translational medicine. 2010; 2(51):51ra70.

21. Dijkgraaf GJ, Alicke B, Weinmann L, Januario T, West K, Modrusan Z, Burdick D, Goldsmith R, Robarge K, Sutherlin D, Scales SJ, Gould SE, Yauch RL and de Sauvage FJ. Small molecule inhibition of GDC-0449 refractory smoothened mutants and downstream mechanisms of drug resistance. Cancer research. 2011; 71(2):435-444.

22. Obeng EA, Carlson LM, Gutman DM, Harrington WJ, Jr., Lee KP and Boise LH. Proteasome inhibitors induce a terminal unfolded protein response in multiple myeloma cells. Blood. 2006; 107(12):4907-4916.

23. Adams J. The proteasome: a suitable antineoplastic target. Nature reviews Cancer. 2004; 4(5):349-360.

24. Adams J. Preclinical and clinical evaluation of proteasome inhibitor PS-341 for the treatment of cancer. Current opinion in chemical biology. 2002; 6(4):493-500. 
25. Moreau P, Richardson PG, Cavo M, Orlowski RZ, San Miguel JF, Palumbo A and Harousseau JL. Proteasome inhibitors in multiple myeloma: 10 years later. Blood. 2012; 120(5):947-959.

26. Reddy $\mathrm{N}$ and Czuczman MS. Enhancing activity and overcoming chemoresistance in hematologic malignancies with bortezomib: preclinical mechanistic studies. Annals of oncology : official journal of the European Society for Medical Oncology / ESMO. 2010; 21(9):1756-1764.

27. Hideshima $\mathrm{T}$, Richardson $\mathrm{PG}$ and Anderson $\mathrm{KC}$. Mechanism of action of proteasome inhibitors and deacetylase inhibitors and the biological basis of synergy in multiple myeloma. Molecular cancer therapeutics. 2011; 10(11):2034-2042.

28. Wright JJ. Combination therapy of bortezomib with novel targeted agents: an emerging treatment strategy. Clinical cancer research : an official journal of the American Association for Cancer Research. 2010; 16(16):4094-4104.

29. Aghajanian C, Dizon DS, Sabbatini P, Raizer JJ, Dupont J and Spriggs DR. Phase I trial of bortezomib and carboplatin in recurrent ovarian or primary peritoneal cancer. Journal of clinical oncology : official journal of the American Society of Clinical Oncology. 2005; 23(25):5943-5949.

30. Ramirez PT, Landen CN, Jr., Coleman RL, Milam MR, Levenback C, Johnston TA and Gershenson DM. Phase I trial of the proteasome inhibitor bortezomib in combination with carboplatin in patients with platinum- and taxaneresistant ovarian cancer. Gynecologic oncology. 2008; 108(1):68-71.

31. Aghajanian C, Blessing JA, Darcy KM, Reid G, DeGeest K, Rubin SC, Mannel RS, Rotmensch J, Schilder RJ and Riordan W. A phase II evaluation of bortezomib in the treatment of recurrent platinum-sensitive ovarian or primary peritoneal cancer: a Gynecologic Oncology Group study. Gynecologic oncology. 2009; 115(2):215-220.

32. Steg AD, Katre AA, Goodman B, Han HD, Nick AM, Stone RL, Coleman RL, Alvarez RD, Lopez-Berestein G, Sood $\mathrm{AK}$ and Landen CN. Targeting the notch ligand JAGGED1 in both tumor cells and stroma in ovarian cancer. Clinical cancer research : an official journal of the American Association for Cancer Research. 2011; 17(17):5674-5685.

33. Han J, Ma I, Hendzel MJ and Allalunis-Turner J. The cytotoxicity of gamma-secretase inhibitor I to breast cancer cells is mediated by proteasome inhibition, not by gammasecretase inhibition. Breast cancer research : BCR. 2009; 11(4):R57.

34. Monticone M, Biollo E, Fabiano A, Fabbi M, Daga A, Romeo F, Maffei M, Melotti A, Giaretti W, Corte G and Castagnola P. z-Leucinyl-leucinyl-norleucinal induces apoptosis of human glioblastoma tumor-initiating cells by proteasome inhibition and mitotic arrest response. Molecular cancer research : MCR. 2009; 7(11):1822-1834.

35. Meng X, Matlawska-Wasowska K, Girodon F, Mazel T, Willman CL, Atlas S, Chen IM, Harvey RC, Hunger SP, Ness SA, Winter SS and Wilson BS. GSI-I (Z-LLNle-CHO) inhibits gamma-secretase and the proteosome to trigger cell death in precursor-B acute lymphoblastic leukemia. Leukemia : official journal of the Leukemia Society of America, Leukemia Research Fund, UK. 2011; 25(7):11351146.

36. Hooper JE and Scott MP. Communicating with Hedgehogs. Nature reviews. 2005; 6(4):306-317.

37. Poruchynsky MS, Sackett DL, Robey RW, Ward Y, Annunziata $\mathrm{C}$ and Fojo T. Proteasome inhibitors increase tubulin polymerization and stabilization in tissue culture cells: a possible mechanism contributing to peripheral neuropathy and cellular toxicity following proteasome inhibition. Cell Cycle. 2008; 7(7):940-949.

38. Santo L, Hideshima T, Kung AL, Tseng JC, Tamang D, Yang M, Jarpe M, van Duzer JH, Mazitschek R, Ogier WC, Cirstea D, Rodig S, Eda H, Scullen T, Canavese M, Bradner J, et al. Preclinical activity, pharmacodynamic, and pharmacokinetic properties of a selective HDAC6 inhibitor, ACY-1215, in combination with bortezomib in multiple myeloma. Blood. 2012; 119(11):2579-2589.

39. Gradilone SA, Radtke BN, Bogert PS, Huang BQ, Gajdos GB and LaRusso NF. HDAC6 inhibition restores ciliary expression and decreases tumor growth. Cancer research. 2013; 73(7):2259-2270.

40. Butler KV, Kalin J, Brochier C, Vistoli G, Langley B and Kozikowski AP. Rational design and simple chemistry yield a superior, neuroprotective HDAC6 inhibitor, tubastatin A. Journal of the American Chemical Society. 2010; 132(31):10842-10846.

41. Steg AD, Bevis KS, Katre AA, Ziebarth A, Dobbin ZC, Alvarez RD, Zhang K, Conner M and Landen CN. Stem cell pathways contribute to clinical chemoresistance in ovarian cancer. Clinical cancer research : an official journal of the American Association for Cancer Research. 2012; 18(3):869-881.

42. Tsubuki S, Kawasaki H, Saito Y, Miyashita N, Inomata $M$ and Kawashima S. Purification and characterization of a Z-Leu-Leu-Leu-MCA degrading protease expected to regulate neurite formation: a novel catalytic activity in proteasome. Biochemical and biophysical research communications. 1993; 196(3):1195-1201.

43. Hubbert C, Guardiola A, Shao R, Kawaguchi Y, Ito A, Nixon A, Yoshida M, Wang XF and Yao TP. HDAC6 is a microtubule-associated deacetylase. Nature. 2002; 417(6887):455-458.

44. Lowe J, Li H, Downing KH and Nogales E. Refined structure of alpha beta-tubulin at 3.5 A resolution. Journal of molecular biology. 2001; 313(5):1045-1057.

45. Duan Z, Feller AJ, Toh HC, Makastorsis $\mathrm{T}$ and Seiden MV. TRAG-3, a novel gene, isolated from a taxol-resistant ovarian carcinoma cell line. Gene. 1999; 229(1-2):75-81.

46. Landen CN, Jr., Lu C, Han LY, Coffman KT, Bruckheimer E, Halder J, Mangala LS, Merritt WM, Lin YG, Gao C, Schmandt R, Kamat AA, Li Y, Thaker P, Gershenson DM, 
Parikh NU, et al. Efficacy and antivascular effects of EphA2 reduction with an agonistic antibody in ovarian cancer. $\mathrm{J}$ Natl Cancer Inst. 2006; 98(21):1558-1570.

47. Steg A, Wang W, Blanquicett C, Grunda JM, Eltoum IA, Wang K, Buchsbaum DJ, Vickers SM, Russo S, Diasio RB, Frost AR, LoBuglio AF, Grizzle WE and Johnson MR. Multiple gene expression analyses in paraffin-embedded tissues by TaqMan low-density array: Application to hedgehog and Wnt pathway analysis in ovarian endometrioid adenocarcinoma. J Mol Diagn. 2006; 8(1):7683.

48. Chou TC and Talalay P. Quantitative analysis of dose-effect relationships: the combined effects of multiple drugs or enzyme inhibitors. Advances in enzyme regulation. 1984; 22:27-55. 